\title{
Simulation of Arc Plasma Gasification Based on Experimental Conditions
}

\author{
Yawen $\mathrm{CaO}^{\mathrm{l},{ }^{*}}$, Bin $\mathrm{Li}^{2}$, Qin Wang ${ }^{3}$, Zhihao Zhang ${ }^{l}$ and Xianwei Han ${ }^{l}$ \\ ${ }^{1}$ Shaanxi Key Laboratory of Plasma Physics and Applied Technology, 710100, Xi'an, China \\ ${ }^{2}$ Academy of Aerospace Propulsion Technology, 710100, Xi'an, China \\ ${ }^{3}$ State Key Laboratory of Clean Energy Utilization, Zhejiang University, 310027, Hangzhou, China
}

\begin{abstract}
An EPJ process simulation model was set up and verified to simulate the plasma gasification process of the medical wastes. The influence of ER value and SAMR value was simulated based on experimental conditions including material feeding rate, furnace temperature and medical waste properties. Results shows that $\mathrm{ER}=0.3$ is a turning point for medical waste plasma gasification. The required input plasma power and volume flow of combustible constituents in syngas reach the maximum at $\mathrm{ER}=0.3$. The balance of syngas composition and required input plasma power should be overall considered. Results shows that the SAMR value mainly influences the amount of $\mathrm{H}$ element and $\mathrm{N}$ element in the system at a fixed ER value, thus influencing the proportions of $\mathrm{H}_{2}$ and $\mathrm{N}_{2}$ in monotonous ways. Input plasma power needed and combustible syngas flow increase with the increasing SAMR.
\end{abstract}

\section{Introduction}

Medical wastes are hazardous wastes produced along with daily medical treatment, which contain large amounts of medical plastics of high polymer like infusion bags, needle tubing and products of plant fibers like masks and cotton swabs. With high organic constituent in medical wastes, the harmless and reclamation disposal of medical wastes can be realized by high temperature gasification.

Arc thermal plasma gasification and melting technology is rising in China recently. Various types of gases flow through the gas passage of the plasma torch and can be ionized by the arc generated at high voltage, forming plasma jet with high temperature and producing a high temperature (usually higher than $1200^{\circ} \mathrm{C}$ ) in gasification furnace which is far higher than conventional heating methods. Organics of the wastes are completely decomposed into small molecules like $\mathrm{CO}, \mathrm{H}_{2}$ and light hydrocarbons under high temperature and reducing atmosphere while inorganic matters are melt and later cooled down to form compact vitreous outside the furnace. As the Arc thermal plasma gasification and melting technology can realize thoroughly harmless, resourceful and reductive disposal, it is suitable to be applied in medical wastes disposal.

Process simulation is set up based on the thermomechanical analysis. Mountouris et $\mathrm{a}^{\left[{ }^{1]}\right.}$ set up an GasifEq model (equilibrium plasma gasification model) to describe the plasma gasification process, made thermomechanical analysis and verified the model; M.Minutillo et $\mathrm{al}^{[2]}$ studied gasification process influenced by different gasification agents using a EPJ(EquiPlasmaJet) model; Mazzoni et $a^{[3]}$ simulated the plasma gasification process of municipal wastes and its blends based on Aspen Plus. In China, some small similar experimental systems are starting running recently and only a few process simulations are reported on sludge, biomass and coal ${ }^{[4]}$. This research did some works on the medical wastes plasma gasification based on EPJ model, aiming to provide some references to application of our self-designed plasma torch with high power and our related updraft plasma gasifier.

\section{Model setup and verification}

\subsection{EPJ model set up}

Process simulation of gasification model set up is usually a zero-dimension model and is set up based on several assumptions: 1) Solid wastes mix uniformly with gasification agents; 2) All reactions reach chemical equilibrium; 3) Reaction temperature is high enough to omit the tar and oil; 4) Ash content does not participate with reactions.

According to the EPJ model ${ }^{[2]}$, the whole plasma gasification process is divided into several parts in an updraft gasifier as material drying, material pyrolysis, high-temperature and low-temperature gasification, split and mixing. The main flow sheet is presented below in Fig.1.

\footnotetext{
* Corresponding author: yawencaox@126.com
} 


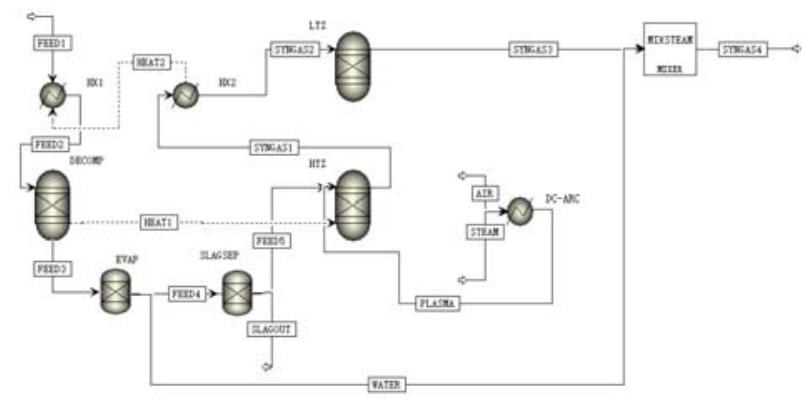

Fig. 1. Main flow of the EPJ model

\subsection{Model verification}

To test the rationality of the model and parameters, the material constituents and conditions used by Minutillo ${ }^{[2]}$ were selected as Table 1 showed.

Table 1. Simulation parameters of verification case $\mathrm{e}^{[2]}$

\begin{tabular}{ccccc}
\hline \multirow{4}{*}{ Wastes } & \multicolumn{2}{c}{ Ultimate analysis\% } & \multicolumn{2}{l}{ Industrial analysis\% } \\
\cline { 2 - 4 } & Cad & 48.23 & Mad & 20 \\
& Had & 6.37 & Aad & 13.81 \\
& Oad & 28.48 & Vad & 75.95 \\
& Nad & 1.22 & FCad & 10.23 \\
& Sad & 0.76 & & \\
& Clad & 1.13 & & \\
Input & Material input rate & \multicolumn{2}{c}{$1 \mathrm{~kg} / \mathrm{s}$} \\
condi- & Plasma input power & \multicolumn{2}{c}{$4.2 \mathrm{MW}$} \\
tions & Gas flow rate & \multicolumn{2}{c}{$0.782 \mathrm{~kg} / \mathrm{s}$} \\
& \multicolumn{2}{c}{ Gas type } & air \\
& Gas temperature & \multicolumn{2}{c}{$2500^{\circ} \mathrm{C}$} \\
& Steam sep ratio & \multicolumn{2}{c}{$85 \%$} \\
& Syngas temperature & \multicolumn{2}{c}{$1240^{\circ} \mathrm{C}$} \\
& Operating pressure & \multicolumn{2}{c}{$1 \mathrm{~atm}$} \\
\hline
\end{tabular}

The comparison of our result and Minutillo result ${ }^{[2]}$ is presented in Table 2. According to the result, there is little error and the model is reliable.

Table 2. Simulation result comparison of EPJ model

\begin{tabular}{ccc}
\hline Constituents & $\begin{array}{c}\text { Simulation } \\
\text { value }(\%, \text { mol })\end{array}$ & $\begin{array}{c}\text { Result from } \\
\text { Minutillo(\%,mol) }\end{array}$ \\
\hline $\mathrm{CO}$ & 33.79 & 33.79 \\
$\mathrm{H}_{2}$ & 21.025 & 21.02 \\
$\mathrm{~N}_{2}$ & 26.957 & 26.96 \\
$\mathrm{CO}_{2}$ & 0 & 0 \\
$\mathrm{H}_{2} \mathrm{O}$ & 11.689 & 11.69 \\
$\mathrm{CH}_{4}$ & 5.988 & 5.99 \\
$\mathrm{HCl}$ & 0.316 & 0.32 \\
$\mathrm{H} 2$ & 0.219 & 0.22 \\
$\mathrm{COS}$ & 0.0156 & 0.02 \\
\hline
\end{tabular}

\section{Plasma gasification simulation of Medical wastes}

\subsection{Material property and parameters}

For the account of operation costs, our self-designed plasma torch is mainly applied in the disposal of medical wastes. Basic properties of typical medical wastes are quoted from research paper of Hongmei $\mathrm{Zhu}^{[5]}$, including the industrial and ultimate analysis of various medical wastes constituents like plastic products as infusion apparatus, injectors and medical gloves, fiber products as cottons, bamboo sticks, gauze and paper masks, besides, possible biological tissues are similarly replaced by the properties of pork liver. According to research paper ${ }^{[5]}$, a typical medical waste composition is $10.34 \%$ infusion apparatus, $8.47 \%$ injectors, $16.88 \%$ medical gloves, $6.21 \%$ cottons, $12.93 \%$ bamboo sticks, $11.49 \%$ gauze, $6.75 \%$ paper masks and $26.93 \%$ biological tissues. According to linear principle of blend constituents, mixture properties of medical waste is calculated as Table 3 shows.

Table 3. Properties of medical wastes

\begin{tabular}{ccccc}
\hline \multirow{4}{*}{ Medical } & \multicolumn{2}{c}{ Ultimate analysis\% } & \multicolumn{2}{c}{ Industrial analysis\% } \\
\cline { 2 - 5 } wastes & Cad & 61.08 & Mad & 4.95 \\
& Oad & 8.59 & Aad & 2.17 \\
& Nad & 3.32 & FCad & 86.78 \\
& Sad & 0.23 & Qad(J/g) & 28199 \\
\hline
\end{tabular}

According to our plasma gasification experiment with our self-designed air arc plasma torch and gasifier as Fig. 2 shows, the power is variable between $30-250 \mathrm{~kW}$, the high and low gasification temperatures are $1700^{\circ} \mathrm{C}$ and $1200^{\circ} \mathrm{C}$ respectively.

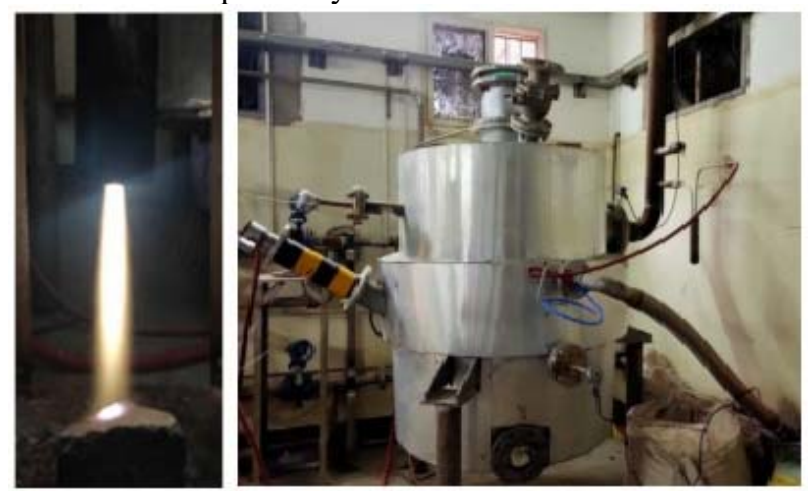

Fig. 2. Air arc plasma torch $(30-250 \mathrm{~kW})$ and gasifier(bottom $1200^{\circ} \mathrm{C}$, top $1700^{\circ} \mathrm{C}$ )

Based on the experimental parameters, gasification process was simulated with variable ER(air equivalence ratio) value and SAMR value(steam and air mass ratio) to provide some references to engineering application ${ }^{[6,7]}$.

Definition of indexes like ER and SAMR are as follows:

$$
\begin{aligned}
& E R=\frac{A i r_{\text {realin }}}{A i r_{\text {thoeryneed }}} \\
& S A M R=\frac{m_{\text {steam }}}{m_{\text {air }}}
\end{aligned}
$$

Where Air realin means the real air flow into the furnace, Air thoeryneed means the air flow needed for completely oxidation, $m_{\text {steam }}$ means the mass flow of steam and $m_{\text {air }}$ means the mass flow of air. 


\subsection{Simulation result and analysis}

\subsubsection{Simulation result with variable ER value}

In simulation of ER influence, the ER values were set from 0.15 to 0.7 , the plasma input power was adjusted to maintain a furnace high-temperature zone of $1700^{\circ} \mathrm{C}$, and the feeding rate of the material was set at $50 \mathrm{~kg} / \mathrm{h}$.

The plasma input power curve varying with the ER value is showed in Fig.3. As the curve in Fig.3 shows, the plasma input power gradually increases to $152 \mathrm{~kW}$ while the ER increases but keeps below 0.3, it is mainly because when ER value is rather low, the whole process is dominated by the endothermic gasification reactions, the heat released by oxidation is too less to compensate the heat needed by the added cold air, so the plasma input power has to increase to maintain the gasification temperature. However, as the ER continuing to increase, the plasma input power lowers down to $22 \mathrm{~kW}$, because partial oxidation reactions release more and more heat to hold the temperature and support the endothermic gasification reactions. It can be foreseen that the process might be self-maintaining when the ER is approaching 1 and the process becomes a combustion reaction due to the high heat value of the material. As the average heat efficiency of the plasma torch is about 0.7 according to our data from cooling system, when the ER value is among $0.15-0.7$, the input plasma power is $22-152 \mathrm{~kW}$, the real torch power is calculated to be $31-217 \mathrm{~kW}$ and can be covered by our plasma torch.

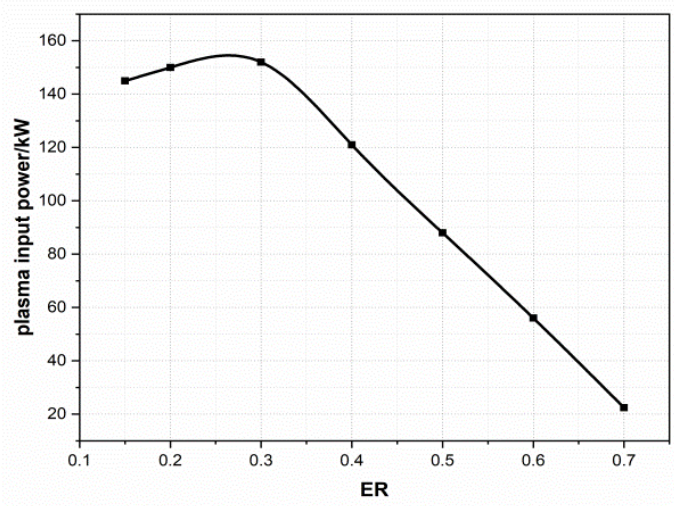

Fig. 3. Plasma input power varying with ER value

Fig.4 shows the gasification products constituents. According to the simulation result, the constituents of gasification products are greatly influenced by the ER value, which shows a gradually deepening degree of the oxidation. As we can see from the Fig. 4, the formation of $\mathrm{H}_{2}$ and $\mathrm{CH}_{4}$ presents obvious competition in cases when ER is lower than $0.3 . \mathrm{CH}_{4}$ decomposes rapidly in the initial stage to form $\mathrm{H}_{2}$ through reaction $\mathrm{CH}_{4}+\mathrm{O}_{2} \rightarrow \mathrm{CO}+\mathrm{H}_{2}$. CO keeps converting to $\mathrm{CO}_{2}$ with ER increasing. A turning point for the process is at $E R=0.3$. The gasification enters a second stage when $\mathrm{H}_{2}$ starts to form $\mathrm{H}_{2} \mathrm{O}$ and $\mathrm{CO}$ accelerates to form $\mathrm{CO}_{2}$ with ER value higher than 0.3 . The share of $\mathrm{N}_{2}$ keeps growing as the air volume increasing and $\mathrm{O}_{2}$ being consumed to raise the oxidation valences.

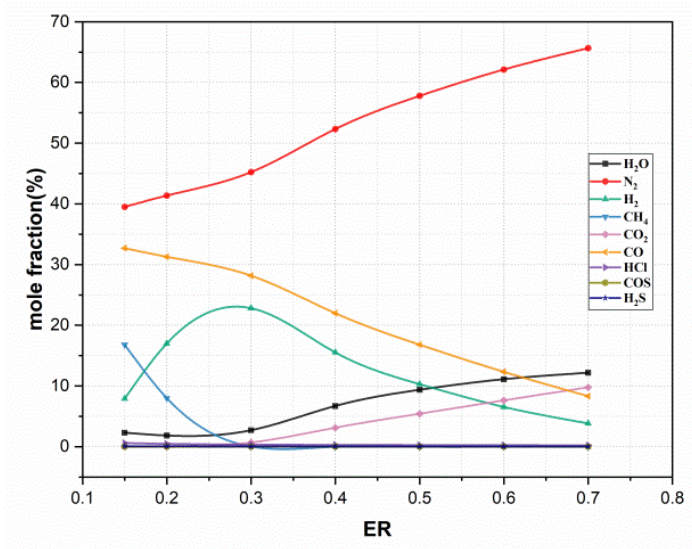

Fig. 4. Gasification products influenced by ER

$\mathrm{CH}_{4}, \mathrm{H}_{2}$ and $\mathrm{CO}$ are combustible and wanted constituents in gasification products, Fig.5 showed the volume flows of the syngas and amount of $\mathrm{CH}_{4}, \mathrm{H}_{2}$ and $\mathrm{CO}$. It can be seen that the volume flow of combustible constituents reaches the maximum of $8.853 \mathrm{~m}^{3} / \mathrm{min}$ at $\mathrm{ER}=0.3$. Synthesize all the simulation results and it can be concluded that the gasification products have best combustibility at $\mathrm{ER}=0.3$, but the required input plasma power also reaches the highest. When choosing a proper ER value, the balance of syngas composition and required input plasma power should be overall considered.

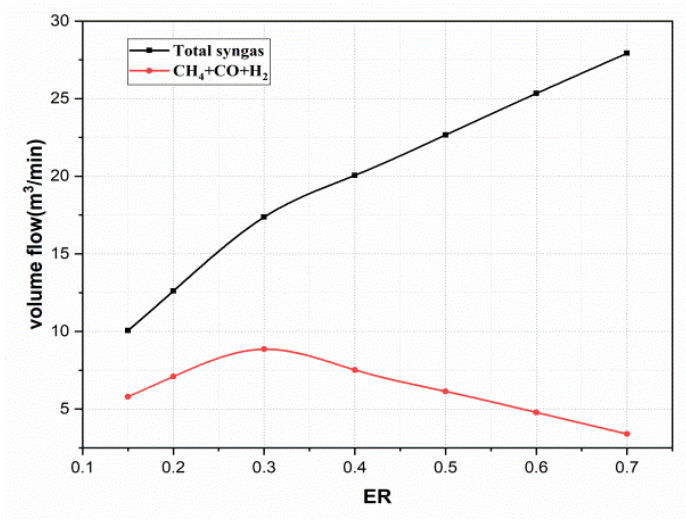

Fig. 5. Syngas volume flow influenced by ER

\subsubsection{Simulation result with variable SAMR value}

To improve the yield of combustible constituents in syngas, steam can be added to the process, partly taking the place of air from an independent inlet or severing as working medium of the plasma torch. To investigate the influence of $\mathrm{H}_{2} \mathrm{O}$, the simulations took the conditions of a fixed ER value of about 0.4 , the plasma input power was adjusted to maintain a furnace high-temperature zone of $1700^{\circ} \mathrm{C}$, the feeding rate of the material was set at $50 \mathrm{~kg} / \mathrm{h}$. SAMR values are solely adjusted to show the influence.

According to simulation result in Fig.6, the required input plasma power increases with the increasing SAMR. This is because that the increasing SAMR strengthens the gasification reactions which are endothermic. 


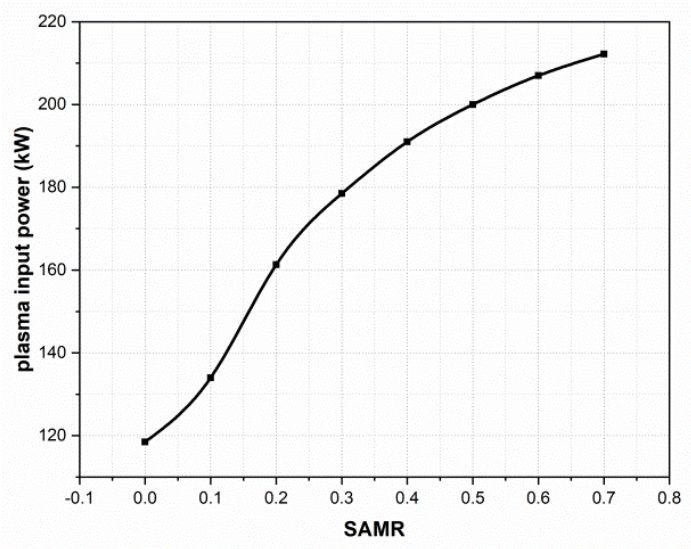

Fig. 6. Plasma input power varying with SAMR value

The constituents of gasification products is showed in Fig.7. As the Fig.7 shows, the proportion of $\mathrm{N}_{2}$ obviously reduces with the increasing SAMR due to the reduction of air and $\mathrm{N}_{2}$, while the proportion of $\mathrm{H}_{2} \mathrm{O}$ increases rapidly at lower SAMR and grows slowly at higher SAMR with more $\mathrm{H}_{2} \mathrm{O}$ takes part in gasification reaction. As a result, the proportion of $\mathrm{H}_{2}$ increases rapidly with more $\mathrm{H}_{2} \mathrm{O}$ fed in. Since the ER value is fixed, the proportions of $\mathrm{CO}$ and $\mathrm{CO}_{2}$ change little with the increasing SAMR. It can be concluded from the simulation results that the variation of SAMR mainly changes the whole ratio of $\mathrm{H}$ element in the system, which leads to the increasing of $\mathrm{H}_{2}$. And the formation of $\mathrm{H}_{2}$ from $\mathrm{H}_{2} \mathrm{O}$ consumes much energy.

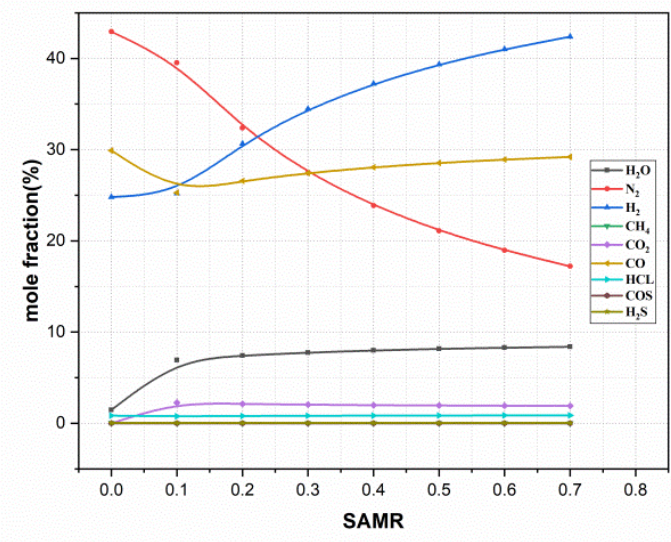

Fig. 7. Gasification products influenced by SAMR

The volume flows of the syngas and amount of $\mathrm{CH}_{4}$, $\mathrm{H}_{2}$ and $\mathrm{CO}$ are showed in Fig. 8.It can be seen from Fig.8 that the volume flow of combustible constituents keeps increasing with the SAMR, while the total gas flow firstly increases and then decreases. This trend can be simply explained by the share gap of $\mathrm{H}_{2}$ increasing and $\mathrm{N}_{2}$ decreasing. SAMR $=0.1$ is apparently a turning point. For more combustible and high heat value syngas, it is obvious that higher SAMR value is a better choice.

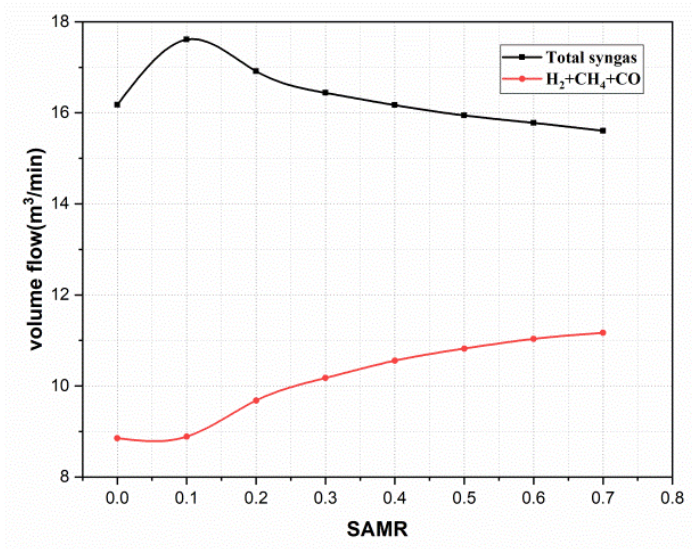

Fig. 8. Syngas volume flow influenced by SAMR

\section{Conclusion}

1) An EPJ process simulation model is set up and the reliability is verified by comparison with a reported case.

2) The influence of ER value is simulated based on experimental conditions. Results showed that $\mathrm{ER}=0.3$ is a turning point for medical waste plasma gasification. The required input plasma power and volume flow of combustible constituents in syngas reach the maximum at $\mathrm{ER}=0.3$. $\mathrm{CH} 4$ decomposes rapidly in the initial stage to form $\mathrm{H} 2$ in cases when ER lower than $0.3, \mathrm{H} 2$ starts to form $\mathrm{H} 2 \mathrm{O}$ and $\mathrm{CO}$ accelerates to form $\mathrm{CO} 2$ with $\mathrm{ER}$ value higher than 0.3 .

3) The influence of SAMR value is simulated based on experimental conditions at a fixed ER value. Results showed that the SAMR value mainly influences the amount of $\mathrm{H}$ element and $\mathrm{N}$ element. Input plasma power needed and combustible syngas flow increases with the increasing SAMR.

\section{Acknowledgements}

This work was supported by National Key R\&D Program of China(No.2019YFC1907000) and National Natural Science Foundation of China(21906144).

\section{References}

1. A. Mountouris, E. Voutsas, D. Tassios., Energy Convers. Manage., 47, 1723-1737 (2006)

2. M. Minutillo, A. Perna , D.D. Bona., Energy Convers. Manage., 50, 2837-2842(2009)

3. L. Mazzoni, I. Janajreh., Int. J. Hydrogen Energy, 30, 19446-19457(2017)

4. C.M. Du, Plasma treatment technology of solid waste(CIP, Beijing, 2018)

5. J.H. Yan, H.M. Zhu, X.G. Jiang, et al, J. Zhejiang Univ., Eng. Sci.,42, 885-889(2008)

6. Q.L. Zhang, L. Dor, W. Yang, et al, Appl. Energy, 90, 106-112(2012)

7. Q.L. Zhang, Y. Wu, L. Dor, et al, Appl. Energy, 2012, 112, 405-413(2013). 